Supplement of Nat. Hazards Earth Syst. Sci., 18, 729-758, 2018

https://doi.org/10.5194/nhess-18-729-2018-supplement

(C) Author(s) 2018. This work is distributed under

the Creative Commons Attribution 4.0 License.

(c) (1)

Supplement of

\title{
Catalogue of extreme wave events in Ireland: revised and updated for 14680 BP to 2017
}

\section{Laura O'Brien et al.}

Correspondence to: Frédéric Dias (frederic.dias@ucd.ie)

The copyright of individual parts of the supplement might differ from the CC BY 4.0 License. 


\section{Supplementary Material}

An interactive map has been created using Google Maps, displaying the wave events discussed in this paper, including those from the original catalogue of extreme waves O'Brien et al. (2013). The map is divided into 4 categories: Storm waves, Rogue waves, Tsunamis and Storm Surges. Lighter coloured markers represent events from the original catalogue O'Brien et al. (2013), while darker colours are used for events identified in this paper.

The map can be found by following this link:

https://drive.google.com/open?id=19cZ59pDHfDnXKYIziYAVWV6AfoE\&usp=sharing 


\section{References}

O’Brien, L., Dudley, J. M., and Dias, F.: Extreme wave events in Ireland: 14680 BP-2012, Natural Hazards and Earth System Science, 13 , 625-648, 2013. 